\title{
Microdeletions on 6p22.3 are associated with mesomelic dysplasia Savarirayan type
}

\author{
Ricarda Flöttmann, ${ }^{1}$ Johannes Wagner, ${ }^{1}$ Karolina Kobus, ${ }^{2}$ Cynthia J Curry, ${ }^{3}$ \\ Ravi Savarirayan, ${ }^{4}$ Gen Nishimura, ${ }^{5}$ Natsuo Yasui, ${ }_{1}^{6}$ Jürgen Spranger, ${ }^{7}$ \\ Hilde Van Esch, ${ }^{8}$ Michael J Lyons, ${ }^{9}$ Barbara R DuPont, ${ }^{9}$ Alka Dwivedi, ${ }^{9}$ \\ Eva Klopocki, ${ }^{10}$ Denise Horn, ${ }^{1}$ Stefan Mundlos, ${ }^{1,2,11}$ Malte Spielmann ${ }^{1,2,11}$
}

\begin{abstract}
- Additional material is published online. To view please visit the journal (http:// dx.doi.org/10.1136/jmedgenet2015-103108)
\end{abstract}

For numbered affiliations see end of article.

\section{Correspondence to} Dr Malte Spielmann, Institute for Medical Genetics and Human Genetics, CharitéUniversitätsmedizin Berlin, Augustenburger Platz 1, 13353 Berlin, Germany; malte.spielmann@charite.de

SM and MS contributed equally to this manuscript.

Received 6 March 2015 Revised 28 April 2015 Accepted 9 May 2015 Published Online First 1 June 2015

\section{CrossMark}

To cite: Flöttmann $\mathrm{R}$, Wagner J, Kobus K, et al. J Med Genet 2015;52: 476-483.

\section{ABSTRACT}

Introduction Mesomelic dysplasias are a group of skeletal disorders characterised by shortness of the middle limb segments (mesomelia). They are divided into 11 different categories. Among those without known molecular basis is mesomelic dysplasia Savarirayan type, characterised by severe shortness of the middle segment of the lower limb.

Objective To identify the molecular cause of mesomelic dysplasia Savarirayan type.

Methods and results We performed array comparative genomic hybridisation in three unrelated patients with mesomelic dysplasia Savarirayan type and identified $2 \mathrm{Mb}$ overlapping de novo microdeletions on chromosome $6 p 22.3$. The deletions encompass four known genes: MBOAT1, E2F3, CDKAL1 and SOX4. All patients showed mesomelia of the lower limbs with hypoplastic tibiae and fibulae. We identified a fourth patient with intellectual disability and an overlapping slightly larger do novo deletion also encompassing the flanking gene ID4. Given the fact that the fourth patient had no skeletal abnormalities and none of the genes in the deleted interval are known to be associated with abnormalities in skeletal development, other mutational mechanisms than loss of function of the deleted genes have to be considered. Analysis of the genomic region showed that the deletion removes two regulatory boundaries and brings several potential limb enhancers into close proximity of ID4. Thus, the deletion could result in the aberrant activation and misexpression of ID4 in the limb bud, thereby causing the mesomelic dysplasia.

Conclusions Our data indicate that the distinct deletion 6p22.3 is associated with mesomelic dysplasia Savarirayan type featuring hypoplastic, triangular-shaped tibiae and abnormally shaped or hypoplastic fibulae.

\section{INTRODUCTION}

Mesomelic dysplasias are a group of skeletal disorders characterised by shortness of the middle limb segments (mesomelia). Currently, 11 different mesomelic and rhizo-mesomelic dysplasias are listed in the Nosology and Classification of Genetic Skeletal Disorders. ${ }^{1}$ So far the underlying molecular defect has been identified in seven mesomelic and rhizo-mesomelic dysplasias. Among those without known molecular basis are mesomelic dysplasia Nievergelt type (Nievergelt syndrome, MIM 163400) and mesomelic dysplasia Savarirayan type
(MIM 605274). Steichen-Gersdorf et $a l^{2}$ described an infant with a phenotype similar to Nievergelt mesomelic dysplasia carrying a $500 \mathrm{~kb}$ microdeletion on chromosome $2 \mathrm{q} 11.1$ containing the gene LAF4. The patient additionally suffered from severe central nervous system dysfunction, and complex malformations of the urogenital tract, resulting in death at the age of 4 months. ${ }^{2}$ A more detailed analysis of the deleted region demonstrated that several exons of the LAF4 gene were deleted in this case, resulting in a truncated LAF4 protein. ${ }^{3}$

Nievergelt syndrome is characterised by severe mesomelic shortness and a triangular or rhomboid shape of the tibiae accompanied by synostosis of the tarsal and metatarsal bones, clubfeet and dysplastic ankle joints. ${ }^{4}$ Short radii, restricted mobility of the elbows, radio-ulnar synostosis and dislocated radial heads are also present. Patients with mesomelic dysplasia Savarirayan type share radiographic features with Nievergelt syndrome such as triangular tibiae and dislocated radial heads. The distinct features however are absence of relative fibular overgrowth and tarsal/metatarsal synostoses as well as presence of other skeletal changes including an abnormal pelvis with dislocated hips. ${ }^{5} 6$

In this study, we show that the distinct deletion $6 \mathrm{p} 22.3$ is associated with mesomelic dysplasia Savarirayan type featuring hypoplastic, oval-shaped or triangular-shaped tibiae and abnormally shaped, hypoplastic or absent fibulae.

\section{CLINICAL REPORTS}

\section{Patient 1}

Detailed clinical and radiological findings of this patient were published by Yasui et $a l^{7}$ (case 2). A 1-year-old boy presented with severe mesomelic shortness of the legs. The parents were nonconsanguineous and there were no teratogenic exposures during the pregnancy. The family history was unremarkable. Born at 38 weeks of gestation, his birth weight $(2.456 \mathrm{~g},-2.1 \mathrm{SD})$ and length $(39.6 \mathrm{~cm},-3.7 \mathrm{SD})$ were abnormal. His motor and speech development was normal. Physical examination at the age of 9 months showed multidirectional instability of knees and ankles, without apparent foot abnormalities. Radiographs of the legs revealed bilateral absence of tibia and fibula. Femora were well developed. There was congenital dislocation of the hips. Tarsal bones were developed normal. ${ }^{7}$ Radiographs, taken at the age of 
Figure 1 Images of patients. Patient 1: note severe mesomelic shortness of the legs (A). Radiograph at the age of 9 months shows hip dislocation, rounded distal femoral epiphyses and two ossifications centres of tibia and fibula (B). Patient 3: note severe mesomelic shortness and bowing of the lower legs (C and D). Radiographs showing markedly short, and dysplastic tibiae and fibulae with triangular shape in ap view as well as hypoplastic pubic bones. The fibulae were more severely affected than the tibiae $(\mathrm{E}-\mathrm{H})$.
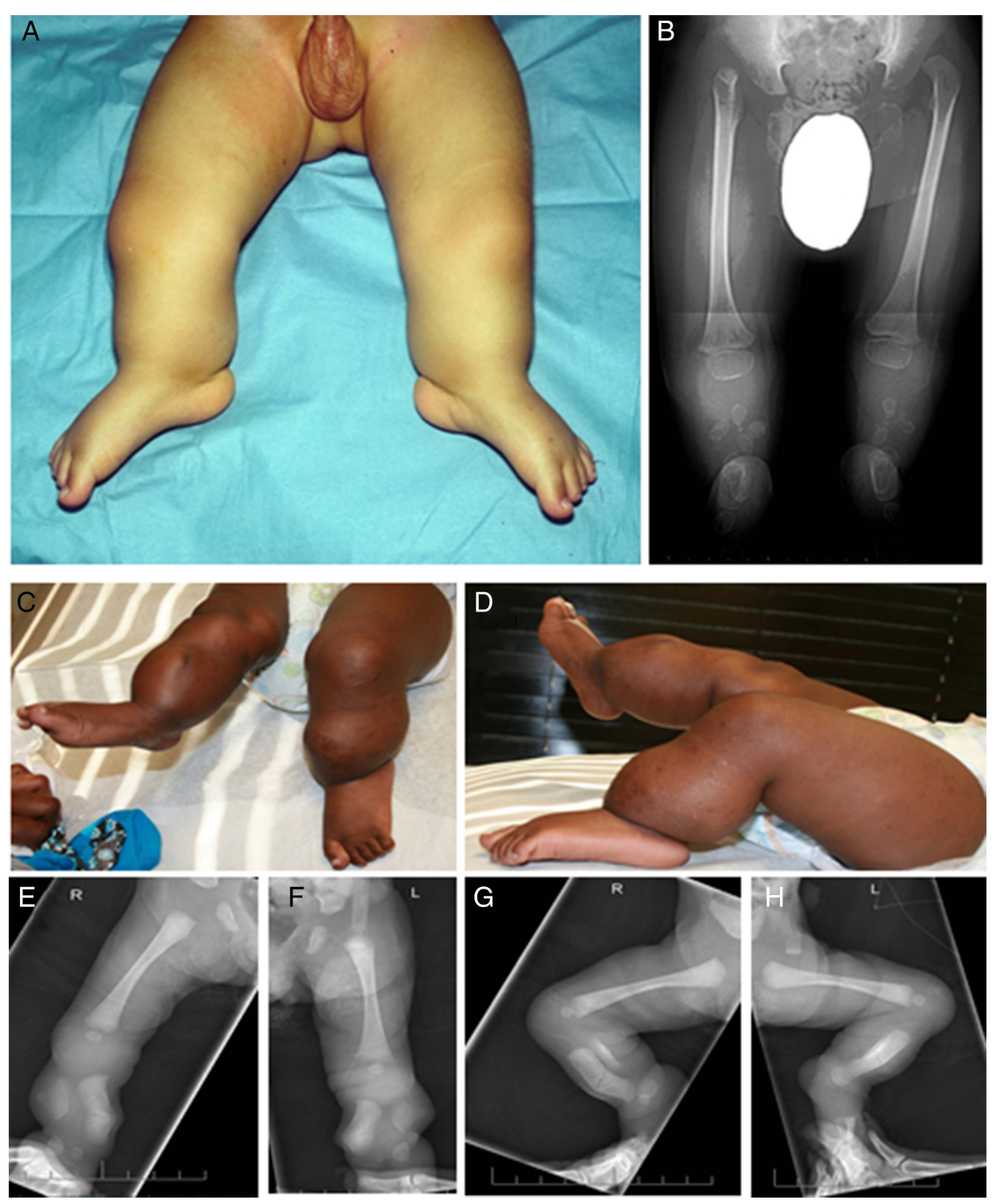

2 years and 10 months, showed two uniting ossifications centres of tibia and fibula (figure 1A, B).

\section{Patient 2}

This patient was published clinically as 'case 1' by Savarirayan et al in $2000 .^{5}$ The girl was the third child of healthy nonconsanguineous parents, and family history was unremarkable. Severe shortness of the lower legs was noted at birth. Development was delayed with crawling at 15 months and first spoken words at the age of 21 months and she required special education. Prominent radial heads and short broad forearms were observed. Supination and pronation of forearms was incomplete. Bilateral equinovalgus foot deformities were present.

Radiographic findings included proportionate shortness of radii and ulnae, absence of fibulae and marked hypoplasia of the tibiae, which were triangular or oval in configuration with the apices/bases projecting towards the skin.

\section{Patient 3}

Patient 3 presented at 11 months old with severe mesomelic shortness of the lower legs. Her lower limb anomalies were first identified on prenatal ultrasound at 5 months' gestation. There were no teratogenic exposures during the pregnancy. She was the only child of non-consanguineous parents. Her father, paternal grandfather and a paternal cousin had bowed legs, but there were no family members with a history of significant limb anomalies. Her development was normal except for gross motor delays related to her lower limb anomalies. Physical examination revealed a normal appearance to her arms. Her lower legs revealed significant mesomelic shortness with anterior tibial bowing. Radiographic findings included hypoplasia of the tibiae and the fibulae, which were very short with a nearly triangular shape at the ap view. The apices projected towards the skin and the fibulae were more severely affected (figure $1 \mathrm{C}-\mathrm{H}$ ). Pubic bones were hypoplastic. Radius and ulnar were well developed.

\section{Patient 4}

This patient presented at age 5 years with mildly delayed motor and expressive speech developmental delay. Growth parameters are along 90-97th centile with normal limb proportions. She had pedes plani but no other skeletal abnormalities. Therefore, no radiographs were obtained. 


\section{METHODS}

\section{Human material}

Venous blood samples were obtained from the patients by standard procedures.

\section{Microarray-based comparative genomic hybridisation (array CGH)}

All experiments were done with genomic DNA extracted from blood samples.

Array comparative genomic hybridisation (array CGH) for patient 1 was carried out using a submegabase whole human genome tiling path BAC array as previously described. ${ }^{8}$ Images were scanned using GenePix 4100A and analysed using GenePix Pro V.6.0 software (Axon Instruments, Foster City, California, USA). Further analyses and visualisation were performed with CGHPRO. ${ }^{9}$ Also, 35882 BACs were included in the analysis. Raw data were normalised by 'Subgrid LOWESS'. The $\log 2$ ratio of test to reference was calculated and plotted according to chromosomal position of the clones. Copy number gains and losses were determined by using a conservative threshold of 0.3 and -0.3 , respectively. Aberrant signals including three or more neighbouring BAC clones were considered as genomic aberrations.

The array CGH result was confirmed by FISH using BAC probes (RP11-86O17, RP11-204E9) located within the deletion on chromosome $6 \mathrm{p}$. The interphase FISH analysis showed only one signal for the probe RP11-86017 in 274/339 interphase nuclei $(81 \%)$ and only one signal for the probe RP11-204E9 in $88 / 102$ interphase nuclei (86\%), respectively. The testing of parents revealed two signals for both probes on chromosome 6 in both parents.

Array CGH for patient 2 was carried out using a wholegenome $1 \mathrm{M}$ oligonucleotide array (Agilent, Santa Clara, California, USA).Also, $1 \mathrm{M}$ arrays were analysed by Feature Extraction V.9.5.3.1 and CytoGenomics V.2.7.8.0 (Agilent, Santa Clara, California, USA). Analysis settings-aberration algorithm: ADM-2; threshold: 6.0 ; window size: $0.2 \mathrm{Mb}$; filter: 5 probes, $\log 2$ ratio $=0.29$. Array CGH for patient 3 was carried out using a whole-genome human SNP Array V.6.0 by Affymetrix, and for patient 4 and the parents a whole genome $180 \mathrm{k}$ CytoSure ISCA array was used. Data were submitted to the DECIPHER database (http://decipher.sanger.ac.uk); accession numbers: $304175,304177,304179$ and $288102 .^{10}$

\section{Quantitative real-time PCR (qPCR)}

qPCR was performed as described previously ${ }^{11}$ using genomic DNA of the index patients and their parents to confirm de novo status. Primer sequences are available upon request.

\section{Sanger sequencing analysis}

Genomic DNA from the patients was extracted from peripheral blood leucocytes using standard protocols. Coding region and flanking intronic sequences of the exons of MBOAT1, E2F3, CDKAL1 and SOX4 were amplified and sequenced. PCR was performed in a total volume of $20 \mu \mathrm{L}$ with $40 \mathrm{ng}$ genomic DNA as template, $2 \mu \mathrm{L} 10 \times$ PCR buffer, $0.6 \mu \mathrm{L}$ deoxynucleotide mix $(10 \mathrm{mM}), 0.5 \mu \mathrm{L}$ primer $(10 \mathrm{pMol} / \mu \mathrm{L}), 0.6 \mu \mathrm{L} \mathrm{MgCl}_{2}(50 \mathrm{mM})$ and $0.2 \mu \mathrm{L}$ Taq polymerase (Rapidozym, Germany). Primers and PCR conditions are available upon request. The PCR products were purified by enzymatic treatment (Exonuclease I, NEB; Shrimp Alkaline Phosphatase, Roche Diagnostics). For the sequencing of the PCR products, the BigDye V.3.1 (Applied Biosystems) sequencing kit was used. PCR products were analysed by capillary automat ABI3730 (Applied Biosystems). The sequencing results were processed by DNA-STAR software (DNA-Star).

\section{Databases and in silico analysis}

We used the databases DECIPHER (https://decipher.sanger.ac.uk/), ClinVar (http://www.ncbi.nlm.nih.gov/clinvar/) and DGV (http:// dgv.tcag.ca/dgv/app/home) to classify the deletions. ${ }^{10} 1213$

The processing of the Hi-C data was performed by the Ren $\mathrm{lab}^{14}$ and downloaded via http://chromosome.sdsc.edu/mouse/ hi-c/download.html.

The Gene Expression Omnibus accession numbers for the ChIP-sequencing data for the H3k27ac enhancer mark reported by Cotney et $a l^{15}$ are GSE42413 and GSE42237.

\section{RESULTS}

In this study, we performed array CGH in three unrelated patients with mesomelic dysplasia Savarirayan type and identified $2 \mathrm{Mb}$ overlapping de novo microdeletions on chromosome $6 \mathrm{p} 22.3$. In a fourth patient with intellectual disability but without skeletal abnormalities, we detected an overlapping slightly larger do novo deletion also encompassing the flanking gene ID4.

For patient 1, array CGH revealed a deletion on chromosome 6 [arr[hg19] 6p22.3 (19964281-22008341)x1] (figure 2). The size of the deletion was about $2 \mathrm{Mb}$ encompassing four known genes: MBOAT1,E2F3, CDKAL1 and SOX4. The result was confirmed by FISH using BAC probes located within the deletion on chromosome 6 . Testing of parents revealed two signals for both probes on chromosome 6 in both parents (see online supplementary figure S1). Therefore, the deletion occurred de novo in patient 1 . For patients 2 and 3, array CGH revealed a similar $2 \mathrm{Mb}$ deletion as in patient 1 [arr[hg19] $6 \mathrm{p} 22.3$ (19974194-22013061)x1] and [arr[hg19] 6p22.3 (1984928021604600)x1], respectively (figure 2). The results were confirmed by qPCR. In patient 2 , the parents were not available for testing, whereas qPCR analysis of the parents revealed a de novo status in patient 3 (see online supplementary figure S1).

For patient 4, array CGH revealed a $2.5 \mathrm{Mb}$ de novo deletion on chromosome 6 [arr[hg19] 6p22.3 (19153 386-21698497) $\mathrm{x} 1]$ (figure 2). The result was confirmed by qPCR, and the deletion encompassed the five genes: MBOAT1, E2F3, CDKAL1, SOX4 and ID4. qPCR analysis of the parents revealed a de novo status (see online supplementary figure $\mathrm{S} 1$ ). The patient also harboured a $540 \mathrm{~kb}$ duplication on $8 \mathrm{p} 23.1$ of unknown significance. This patient did not show any skeletal abnormalities. All positions are listed in detail table 2.

The overlapping deletions on chromosome 6p22.3, as well as another case published by Landinsky et $a l^{16}$ in 2014, are shown in figure 3. Mutations on the second allele were excluded by sequencing of all exons and splice sites of patients 2 and 3 . The phenotypic characteristics of our patients and the patient described by Ladinsky et al are compared in table 1 .

The DECIPHER database lists four other patients with overlapping, but much larger, deletions. ${ }^{10}$ None of those patients had significant skeletal abnormalities. In two of them, the phenotype was given in detail and did not include any significant skeletal abnormalities (accession numbers: 249613 and 263354). The deletions were much larger with 4.8 and $10.6 \mathrm{Mb}$ and encompassed 20 and 68 genes, respectively. One patient was diagnosed with intellectual disability, autism, downslanting palpebral fissures and muscular hypotonia, whereas the other was described to have several dysmorphic features and atrophy/ degeneration of corpus callosum. Inheritance and pathogenicity 


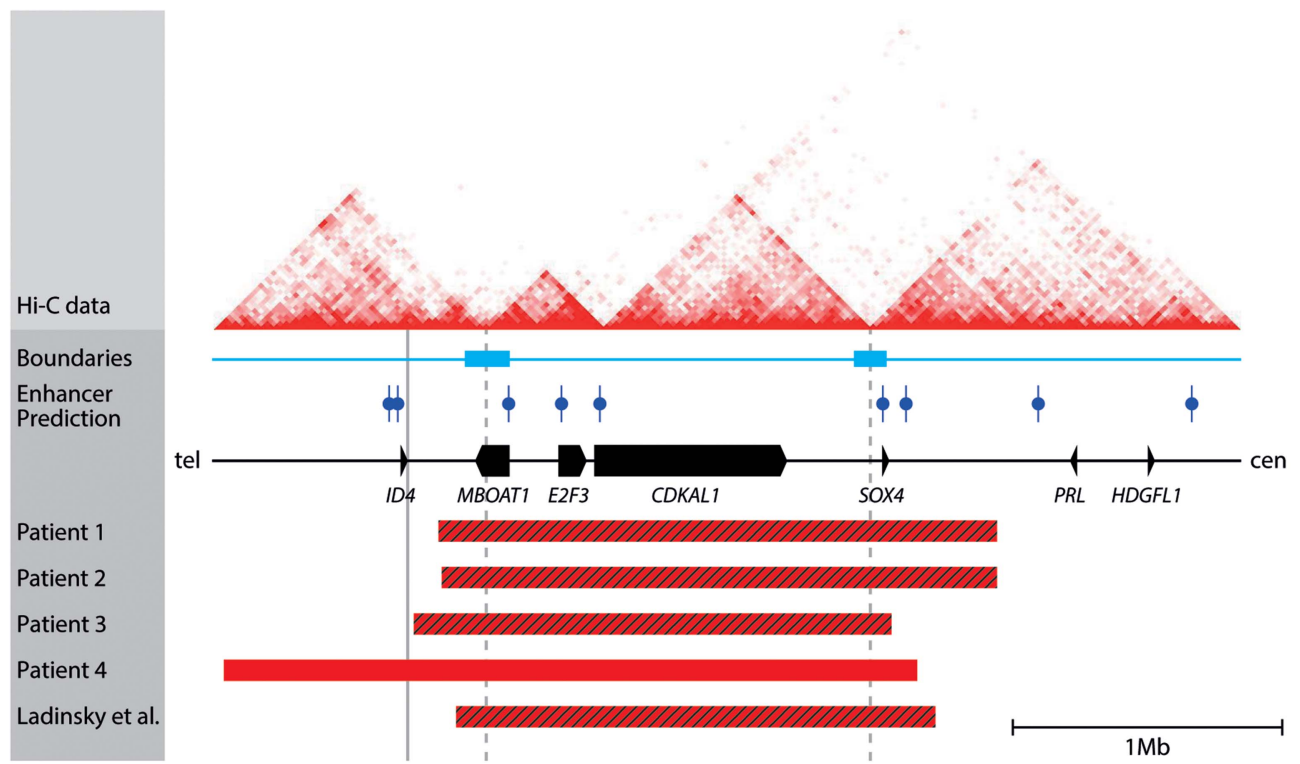

Figure 2 Genomic locus of the deleted region 6p22.3. Centromeric is right, telomeric left. Genes and their direction of transcription are indicated by black boxes/arrows. Potential boundaries of topologically associated domains (TADs) (red triangles, top) according to Dixon et al ${ }^{14}$ are indicated by light blue boxes on top. Thin broken vertical lines indicate the TAD boundaries. H3k27ac enhancer marks (enhancer prediction) are indicated by blue marks above the gene symbol. ${ }^{15}$ Note that several of these marks are located centromeric of the deletion. The deletions reported here are shown below the gene symbols, indicated by red/black bars (patients 1, 2 and 3). A grey vertical line indicates that ID4 is not deleted in patient 3. All three patients showed severe mesomelic shortness of the lower legs. The deletions encompass four protein coding genes: MBOAT1, E2F3, CDKAL1 and SOX4 on chromosome 6 p22.3. A similar, recently published family is shown below. ${ }^{16}$ In this study, a fourth patient was found to have a slightly larger deletion extending further distal, encompassing also the telomeric gene ID4, without any skeletal abnormalities (red bar). The deletions associated with mesomelic dysplasia remove two regulatory boundaries and bring several limb enhancers into close proximity of ID4. Thus, the deletions could result in the aberrant activation and misexpression of ID4 in the limb bud, thereby causing the mesomelic dysplasia.

was listed as unknown and as de novo with unknown pathogenicity, respectively. Two more had no phenotype given, but the responsible clinicians were contacted and it was confirmed that there were no major skeletal abnormalities (accession numbers: 256653 and 285668). Therefore, no radiographs of the legs were obtained. One of these patients was diagnosed with developmental delay, heart defects, short neck and eye abnormalities and was published by Bremer et al. ${ }^{17}$ The other patient presented with intellectual disability; inheritance was unknown but pathogenicity was listed as definitely pathogenic. The deletions were 7.3 and $4 \mathrm{Mb}$ and encompassed 45 and 20 genes, respectively. ClinVar lists only one overlapping $12 \mathrm{Mb}$ deletion in a patient with developmental delay (dbVar: nsv530892). ${ }^{12}$ The database of genomic variants does not list entries that encompass the complete region. ${ }^{13}$ The largest described deletion was found in 1 out of 95 healthy individuals and spans $20 \mathrm{~kb}$ between CDKAL1 and SOX4. All other annotated structural variations are considerably smaller.

\section{DISCUSSION}

We identified three unrelated patients with mesomelic dysplasia and overlapping microdeletions encompassing four protein coding genes: MBOAT1, E2F3, CDKAL1 and SOX4 (figure 3). All patients showed severely hypoplastic tibiae and fibulae. In one case, the fibulae were rhomboid shaped, whereas in the others the fibulae were hypoplastic and fragmented. The radial and ulnar bones were also affected by mild shortness in patient 2. Further signs were hip dislocation and radial head anomalies (radial head dislocation in patient 1 and prominent radial head in patient 2). Considering the many overlapping features, these three cases can be classified as mesomelic dysplasia Savarirayan type. Patient 3 also shares similarities with Nievergelt syndrome in particular with regard to the presence of triangular-shaped fibulae and tibiae. However, in contrast to Nievergelt syndrome, relative elongation of fibulae and tarsal and tibia-fibular synostosis were not present.

Our data show that the distinct deletion at $6 \mathrm{p} 22.3$ is associated with mesomelic dysplasia Savarirayan type characterised by hypoplastic, oval-shaped or triangular-shaped tibiae and fibulae. A fourth case with an overlapping microdeletion and striking clinical as well as radiological similarities was recently published. ${ }^{16}$ This patient additionally presented with hypereosinophilic syndrome, sensorineural hearing loss due to malformation of the semicircular canals and mild craniofacial dysmorphic features. Our patient 2 was diagnosed with global developmental delay. Patient 4, carrying a de novo $2.5 \mathrm{Mb}$ overlapping deletion encompassing MBOAT1, E2F3, CDKAL1, SOX4, and additionally ID4, also presented with global developmental delay but without skeletal malformations. Interestingly, the DECIPHER database lists four other patients with overlapping, but much larger, deletions between 4 and $10 \mathrm{Mb}^{10}$ None of those patients had significant skeletal abnormalities, and three were diagnosed with intellectual disability or developmental delay.

The MBOAT1 (membrane bound O-acyltransferase domain containing 1 gene) gene belongs to the membrane-bound O-acetyltransferase superfamily. ${ }^{18}$ It was shown to be disrupted by a translocation in a patient with short stature and brachydactyly. ${ }^{19}$ However, no further mutations have been reported in this gene to this date. E2F3 (E2F transcription factor 3) is expressed in the developing limb buds, but no skeletal abnormalities were reported in knockout mice. ${ }^{20-22}$ The protein encoded by CDKAL1 (CDK5 regulatory subunit associated protein 1-like 1) is a member of the methylthiotransferase family. Inactivation in the mouse is associated with abnormalities in insulin secretion but not with abnormal limbs. ${ }^{23}$ SOX4 (sex determining region on Y-box 4) is expressed in the 


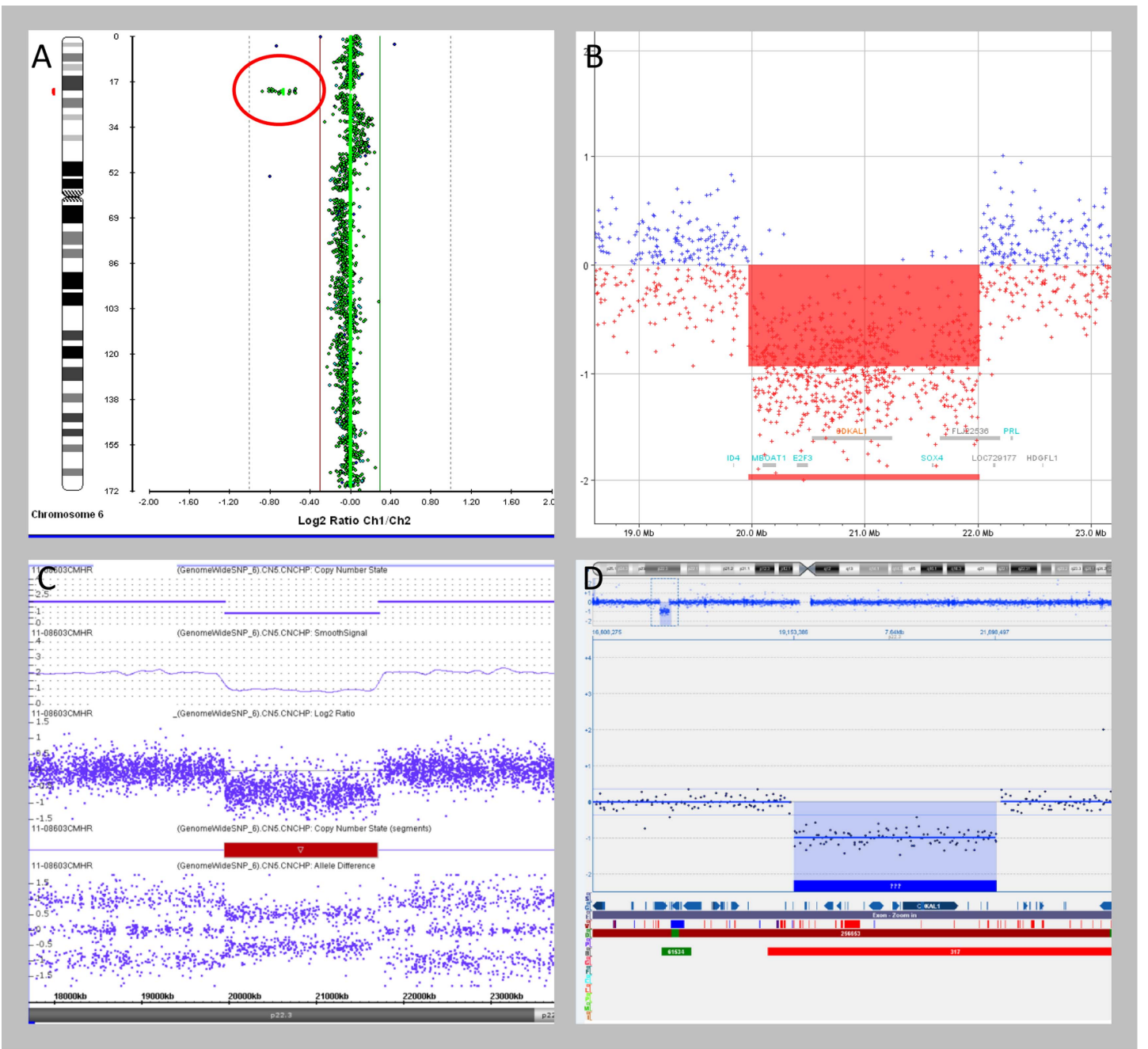

Figure 3 Results of array comparative genomic hybridisation (CGH). Array CGH was carried out using a submegabase whole human genome tiling path BAC array in patient 1: arr[hg19] 6p22.3 (19964281-22008341)x1 (A). Array CGH for patient 2 was carried out using a whole-genome 1 M oligonucleotide array (Agilent, Santa Clara, California, USA): arr[hg19] 6p22.3 (19974194-22013061)x1 (B). Array CGH for patient 3 was carried out using a whole-genome human SNP Array 6.0 by Affymetrix: Patient 3 arr[hg19] 6p22.3 (19849280-21604600)x1 (C). Array CGH for patient 4 was carried out using the whole-genome 180k CytoSure ISCA array: arr[hg19] 6p22.3 (19153386-21698497)x1 (D). All experiments were done with genomic DNA extracted from blood samples. The results and de novo statuses were confirmed by FISH or qPCR (see figure S1) and detailed information for the genomic positions are listed in table 2.

developing limb buds and a key player in cartilage and bone development. $^{24} 25$ However, previous studies showed that SOX $4^{--}$mice die at embryonic E14.5 from heart defects and do not show any abnormalities of the limbs. ${ }^{26}$ The heterozygous knockout mice did not show any obvious phenotypes and were indistinguishably from their wild-type littermates. ${ }^{20-2326}$ None of the patients were reported to have any cardiac abnormalities.

To further classify the genes deleted in our patient, we included the haploinsufficiency score (HI index) of the particular genes ${ }^{27}$ : high ranks (eg, 0-10\%) indicate a gene is more likely to exhibit HI, and low ranks (eg, 90-100\%) indicate a gene is more likely to not exhibitHI. ${ }^{27}$ While MBOAT1 and CDKAL1 exhibiting scores of 70.2 and 43.9, respectively, are unlikely to cause the phenotype, E2F3 and SOX4 are part of bone and limb development and have low HI scores of 4.5 and 2.5. Nevertheless, the absence of limb defects in the E2F3 and SOX4 knockout mice makes them unlikely candidates to cause mesomelic dysplasia. Mutations on the second allele were excluded by sequencing of all exons and splice sites.

Patients 2 and 4 showed, in addition to their skeletal abnormalities, developmental delay. All genes within the deletion
(MBOAT1, CDKAL1, E2F3 and SOX4) show strong expression during brain development and have to be considered as candidates for developmental delay. ${ }^{28}$ The DECIPHER database lists one very small deletion encompassing only one coding exon of CDKAL1 in a patient with neonatal hypotonia and seizures (patient 294851). Neonatal hypotonia could be a sign of early developmental delay and therefore one could speculate that CDKAL1 might be a candidate gene for developmental delay and seizures.

It is striking that patient 4 has no skeletal abnormalities but harbours an overlapping but only slightly larger deletion that also includes the ID4 gene.

Although it cannot be ruled out that the phenotypic differences between patients $1-3$ and patient 4 reflect low penetrance or even variable expressivity of $\mathrm{HI}$ of the deleted genes, we think that other molecular mechanisms besides gene-dosage effects have to be considered. One mutational mechanism to be considered is the aberrant activation by enhancers that were moved by the deletion in close proximity to the new target gene, a mechanism known as enhancer adoption. ${ }^{29}$ Data from genome-wide chromosome conformation capture analysis indicate that the 
Table 1 Phenotypic characteristics of our patients and the patient described by Ladinsky et al

\begin{tabular}{|c|c|c|c|c|}
\hline & Patient 1 & Patient 2 & Patient 3 & Ladinsky et al \\
\hline \multicolumn{5}{|l|}{ Clinical features } \\
\hline Upper limbs & Bilateral subluxation of radial heads & $\begin{array}{l}\text { Short, broad forearms with prominent radial heads } \\
\text { and normal hands }\end{array}$ & Normal & NA \\
\hline Femur & Normal & Normal & Normal & NA \\
\hline Patellae & Palpable & Palpable & NA & NA \\
\hline Lower leg & Mesomelic shortened & Mesomelic shortened with bowing & Mesomelic shortened & Mesomelic shortened \\
\hline Feet & Normal & Equinovalgus foot deformity & Normal & NA \\
\hline \multicolumn{5}{|l|}{ Radiological findings } \\
\hline Upper limbs & NA & $\begin{array}{l}\text { Proportionate shortness of radii and ulnae; ulnae } \\
\text { proximally widened; humeri and phalanges normal }\end{array}$ & Normal & NA \\
\hline Hips & Congenital dislocation & $\begin{array}{l}\text { Dislocated, ilia increased in height and decreased in } \\
\text { width, with widened sacro-sciatic notches; acetabular } \\
\text { roofs were hypoplastic }\end{array}$ & Hypoplastic pubic bones & Left hip dysplasia \\
\hline Femur & Well-developed, rounded distal femoral epiphysis, & Normal, rounded distal femoral epiphysis & Well-developed & NA \\
\hline Tibia and fibula & $\begin{array}{l}\text { Cartilaginous remnants of tibia and fibula, each with two } \\
\text { ossification centres, which united to form short diaphyses } \\
\text { (at age } 2 \text { years, } 10 \text { months) }\end{array}$ & $\begin{array}{l}\text { Absence of fibulae; hypoplastic, oval-shaped tibia } \\
\text { abutting the anterior surface of the shin } \\
\text { (at age } 21 \text { months) }\end{array}$ & $\begin{array}{l}\text { Shortening and deformity of tibiae, } \\
\text { hypoplastic and nearly triangular } \\
\text { shaped fibulae }\end{array}$ & $\begin{array}{l}\text { Described as 'hemimelia'(apparent } \\
\text { hypoplastic and oval-shaped tibiae } \\
\text { and absent fibulae) }\end{array}$ \\
\hline Feet & Normally developed tarsal bones & $\begin{array}{l}\text { Equinus deformities of the feet, tarsal bones and } \\
\text { metatarsals were normal }\end{array}$ & Normal & NA \\
\hline \multicolumn{5}{|l|}{ Other features } \\
\hline Other features & NA & $\begin{array}{l}\text { Bilateral supernumerary nipples, several Mongolian } \\
\text { spots }\end{array}$ & None & $\begin{array}{l}\text { Plagiocephaly, facial dysmorphisms, sensorineural } \\
\text { hearing loss, heart defect Hypereosinophilic } \\
\text { syndrome }\end{array}$ \\
\hline Development & Normal & Globally delayed & Normal & NA \\
\hline
\end{tabular}


Table 2 Genomic positions of the deletions on 6p22.3 (arr[hg19])

\begin{tabular}{lllll}
\hline & $\begin{array}{l}\text { Last copy number neutral } \\
\text { probe-telomeric }\end{array}$ & $\begin{array}{l}\text { Most distant probes within the } \\
\text { deletion on 6p22.3 arr[hg19] }\end{array}$ & $\begin{array}{l}\text { Last copy number neutral } \\
\text { probe-centromeric }\end{array}$ & Deleted genes \\
\hline Patient 1 & 19910613 & $19964281-22008394$ & 22072989 & MBOAT1, E2F3, CDKAL1 and SOX4 \\
Patient 2 & 19965294 & $19974194-22013061$ & 22016585 & MBOAT1,E2F3, CDKAL1 and SOX4 \\
Patient 3 & 19840492 & $19849280-21604600$ & 21630684 & MBOAT1, E2F3, CDKAL1 and SOX4 \\
Patient 4 & 19143048 & $19153386-21698497$ & 21711233 & MBOAT1, E2F3, CDKAL1, SOX4 and additionally ID4 \\
\hline
\end{tabular}

Patients 1-3 are affected by mesomelic dysplasia Savarirayan type while patient 4 showed no skeletal abnormalities.

human genome is divided into conserved self-interacting regions called topologically associated domains (TADs), which are separated by regulatory boundary elements. ${ }^{14}$ In this situation, the deletion removes the original target gene and allows enhancers from neighbouring domains to ectopically activate nearby genes. $^{30} \mathrm{~A}$ similar pathomechanism was described to cause Liebenberg syndrome, a rare upper limb malformation ${ }^{31}$ and autosomal-dominant leukodystrophy. ${ }^{32}$ Ibn-Salem et al ${ }^{33}$ demonstrated that in up to $11 \%$ of all deletions reported in the DECIPHER database the phenotype could be best explained by enhancer adoption or a combination of gene-dosage effects and enhancer adoption. In a recent study, Lupiáñez et al demonstrated that deletions of TADs boundaries in humans and mice can cause rewiring of long-range regulatory architecture and result in pathogenic phenotypes. Their results provide the molecular framework to understand the impact of enhancer adoption as mutational mechanism in congenital disorders. ${ }^{34}$

To identify potential limb enhancer elements in the region of the deletions, we analysed ChIP-sequencing data published by Cotney et al. ${ }^{15}$ In their study, they performed genome-wide mapping of the histone modification $\mathrm{H} 3 \mathrm{~K} 27 \mathrm{ac}$ in human embryonic limb tissue and demonstrated that many of the peaks show in vivo enhancer activity in a transgenic mouse assay. ${ }^{15}$ As shown in figure 3, several H3k27ac enhancer marks map into the region of the deletions detected in our patients. We identified at least two potential limb enhancer regions marked by the H3k27ac enhancer mark the map telomeric to the deletions into the regulatory domain of SOX4 (figure 3). Through the deletion of SOX4 and two regulatory boundaries, these potential limb enhancer elements are free to act on other neighbouring genes, that is, ID4. This may result in misexpression of ID4 in the limbs causing skeletal abnormalities in the patients. The proposed misexpression is unlikely to be caused by individual enhancer elements but rather by a cluster of enhancer elements (regulatory landscapes) causing enhancer adoption. ID4 (inhibitor of DNA binding 4) is a member of the inhibitor of DNA binding (ID) protein family and is expressed in the developing limb buds. ${ }^{20}$ It was shown to have a molecular function in osteoblast differentiation, and ID4 ${ }^{-/}$ - mice showed severe growth retardation and died by 5 weeks. ${ }^{35}$ Misexpression of ID4 in the developing bones may thus have a negative effect on bone growth in the limbs, ultimately resulting in mesomelic dysplasia. However, the exact molecular mechanism of the deletion remains to be elucidated. Deletions of regulatory boundaries and/or cis-regulatory elements could also affect the expression of other genes at the locus such as PRL, HDGFL1, NRSN and DCDC2 and thereby contribute to the phenotype.

A growing number of non-coding regulatory mutations are being identified in congenital disease. ${ }^{31-33}$ Our data in combination with the molecular findings by Lupiáñez et $a l^{34}$ show that mutations and structural variations outside of the coding genome can interfere with normal gene regulation by disrupting the regulatory landscape. Therefore, the regulatory landscape of the genome has also to be taken into consideration when investigating the pathology of human disease. Exome sequencing studies in the remaining mesomelic dysplasias as well as in other skeletal dysplasias have failed to identify coding mutations in many cases. Therefore, regulatory and non-coding mutations need to be considered in the development of these entities. Furthermore, new model systems need to be developed to study the molecular effects of regulatory mutations.

In summary, we show that the distinct deletion $6 \mathrm{p} 22.3$ is associated with mesomelic dysplasia Savarirayan type featuring hypoplastic, oval-shaped or triangular-shaped tibiae and abnormally shaped, hypoplastic or absent fibulae.

\section{Author affiliations}

${ }^{1}$ Institute for Medical Genetics and Human Genetics, Charité Universitätsmedizin Berlin, Berlin, Germany

${ }^{2}$ Max Planck Institute for Molecular Genetics, Berlin, Germany

${ }^{3}$ Institute for Clinical Genetics, UCFS Fresno, California, USA

${ }^{4}$ Victorian Clinical Genetics Service, Royal Children's Hospital, Melbourne, Victoria, Australia

${ }^{5}$ Department of Pediatric Imaging, Tokyo Metropolitan Children's Medical Center, Tokyo, Japan

${ }^{6}$ Tokushima University Hospital, Tokushima, Japan

${ }^{7}$ Children's Hospital, University of Mainz, Mainz, Germany

${ }^{8}$ Center for Human Genetics, University Hospitals Leuven, Leuven, Belgium

${ }^{9}$ Greenwood Genetic Center, Greenwood, South Carolina, USA

${ }^{10}$ Institute for Human Genetics, Biozentrum, Universität Würzburg, Würzburg, Germany

${ }^{11}$ Berlin-Brandenburg School for Regenerative Therapies (BSRT), Berlin, Germany

Acknowledgements We would like to thank the families for their collaboration and contribution to this project as well as Fabienne Pritsch for her technical work.

Contributors Patient recruitment and phenotyping: RF, CJC, RS, GN, NY, JS, HVE, MJL, DH, SM and MS. Array-CGH experiments and analysis: RF, JW, KK, EK, BRD, AD, SM and MS. All the authors contributed in writing and reviewing the manuscript.

Funding This work was supported by a grant from the Deutsche Forschungsgemeinschaft (DFG) grant number KL 2158/2-2 to SM. MS was supported by a fellowship of the Berlin-Brandenburg School for Regenerative Therapies (BSRT), Berlin, Germany.

Competing interests None declared.

\section{Patient consent Obtained.}

Ethics approval Charité Universitätsmedizin Berlin ethics committee.

Provenance and peer review Not commissioned; externally peer reviewed.

\section{REFERENCES}

1 Warman ML, Cormier-Daire V, Hall C, Krakow D, Lachman R, LeMerrer M, Mortier G, Mundlos S, Nishimura G, Rimoin DL, Robertson S, Savarirayan R, Sillence $D$, Spranger J, Unger S, Zabel B, Superti-Furga A. Nosology and classification of genetic skeletal disorders: 2010 revision. Am J Med Genet A 2011;155A:943-68.

2 Steichen-Gersdorf E, Gassner I, Superti-Furga A, Ullmann R, Stricker S, Klopocki E, Mundlos $S$. Triangular tibia with fibular aplasia associated with a microdeletion on 2q11.2 encompassing LAF4. Clin Genet 2008;74:560-5.

3 Kraft K, Geuer S, Will AJ, Chan WL, Paliou C, Borschiwer M, Harabula I, Wittler L, Franke M, Ibrahim DM, Kragesteen BK, Spielmann M, Mundlos S, Lupianez DG, Andrey G. Deletions, Inversions, Duplications: Engineering of Structural Variants using CRISPR/Cas in Mice. Cell Rep Published Online First: 4 Feb 2015. 
4 Hess OM, Goebel NH, Streuli R. Familial mesomelial dwarfism (Nievergelt syndrome). Schweizerische medizinische Wochenschrift 1978;108:1202-6.

5 Savarirayan R, Cormier-Daire V, Curry CJ, Nashelsky MB, Rappaport V, Rimoin DL, Lachman RS. New mesomelic dysplasia with absent fibulae and triangular tibiae. Am J Med Genet 2000;94:59-63.

6 Nakamura M, Matsuda Y, Higo M, Nishimura G. A family with an autosomal dominant mesomelic dysplasia resembling mesomelic dysplasia Savarirayan and Nievergelt types. Am J Med Genet A 2007;143A:2079-81.

7 Yasui N, Nakase T, Sahara W, Ochi T, Okumura E, Sato M. Congenital transverse deficiency of the tibia and fibula: a report of two cases. Skeletal Radiol 2000;29:243-6.

8 Klopocki E, Neumann LM, Tonnies H, Ropers HH, Mundlos S, Ullmann R. Ulnar-mammary syndrome with dysmorphic facies and mental retardation caused by a novel 1.28 Mb deletion encompassing the TBX3 gene. Eur J Hum Genet 2006;14:1274-9.

9 Chen W, Erdogan F, Ropers HH, Lenzner S, Ullmann R. CGHPRO -- a comprehensive data analysis tool for array CGH. BMC Bioinformatics 2005;6:85.

10 Firth HV, Richards SM, Bevan AP, Clayton S, Corpas M, Rajan D, Van Vooren S, Moreau Y, Pettett RM, Carter NP. DECIPHER: database of chromosomal imbalance and phenotype in humans using ensembl resources. Am J Hum Genet 2009;84:524-33.

11 Klopocki E, Ott CE, Benatar N, Ullmann R, Mundlos S, Lehmann K. A microduplication of the long range $\mathrm{SHH}$ limb regulator (ZRS) is associated with triphalangeal thumb-polysyndactyly syndrome. J Med Genet 2008;45:370-5.

12 Landrum MJ, Lee JM, Riley GR, Jang W, Rubinstein WS, Church DM, Maglott DR. ClinVar: public archive of relationships among sequence variation and human phenotype. Nucleic Acids Res 2014;42(Database issue):D980-5.

13 MacDonald JR, Ziman R, Yuen RK, Feuk L, Scherer SW. The Database of Genomic Variants: a curated collection of structural variation in the human genome. Nucleic Acids Res 2014:42(Database issue):D986-92.

14 Dixon JR, Selvaraj S, Yue F, Kim A, Li Y, Shen Y, Hu M, Liu JS, Ren B. Topological domains in mammalian genomes identified by analysis of chromatin interactions. Nature 2012;485:376-80

15 Cotney J, Leng J, Yin J, Reilly SK, DeMare LE, Emera D, Ayoub AE, Rakic P, Noonan $J P$. The evolution of lineage-specific regulatory activities in the human embryonic limb. Cell 2013;154:185-96.

16 Ladinsky HT, Elizalde A, Schickler R, Dees PB, Crenshaw ML, Sleasman JW. Hypereosinophilic syndrome and hemimelia in a patient with chromosome $6 \mathrm{p} 22.3$ deletion. Pediatr Allergy Immunol 2014:25:500-3.

17 Bremer A, Schoumans J, Nordenskjold M, Anderlid BM, Giacobini M. An interstitial deletion of 7.1 Mb in chromosome band 6 p22.3 associated with developmental delay and dysmorphic features including heart defects, short neck, and eye abnormalities. Eur J Med Genet 2009;52:358-62.

18 Shindou H, Shimizu T. Acyl-CoA:lysophospholipid acyltransferases. J Biol Chem 2009:284:1-5.

19 Dauwerse JG, de Vries BB, Wouters CH, Bakker E, Rappold G, Mortier GR, Breuning $\mathrm{MH}$, Peters DJ. A t(4;6)(q12;p23) translocation disrupts a membrane-associated 0-acetyl transferase gene (MBOAT1) in a patient with a novel brachydactyly-syndactyly syndrome. Eur J Hum Genet 2007;15:743-51.

20 Gray PA, Fu H, Luo P, Zhao Q, Yu J, Ferrari A, Tenzen T, Yuk DI, Tsung EF, Cai Z, Alberta JA, Cheng LP, Liu Y, Stenman JM, Valerius MT, Billings N, Kim HA, Greenberg ME, McMahon AP, Rowitch DH, Stiles CD, Ma Q. Mouse brain organization revealed through direct genome-scale TF expression analysis. Science 2004;306:2255-7.

21 Humbert PO, Verona R, Trimarchi JM, Rogers C, Dandapani S, Lees JA. E2f3 is critical for normal cellular proliferation. Genes Dev 2000;14:690-703.
22 Cloud JE, Rogers C, Reza TL, Ziebold U, Stone JR, Picard MH, Caron AM, Bronson RT, Lees JA. Mutant mouse models reveal the relative roles of E2F1 and E2F3 in vivo. Mol Cell Biol 2002;22:2663-72

23 Okamura T, Yanobu-Takanashi R, Takeuchi F, Isono M, Akiyama K, Shimizu Y, Goto M, Liang YQ, Yamamoto K, Katsuya T, Fujioka A, Ohnaka K, Takayanagi R, Ogihara T, Yamori Y, Kato N. Deletion of CDKAL1 affects high-fat diet-induced fat accumulation and glucose-stimulated insulin secretion in mice, indicating relevance to diabetes. PloS ONE 2012;7:e49055.

24 Gyurjan I, Sonderegger B, Naef F, Duboule D. Analysis of the dynamics of limb transcriptomes during mouse development. BMC Dev Biol 2011;11:47.

25 Sekiya I, Vuoristo JT, Larson BL, Prockop DJ. In vitro cartilage formation by human adult stem cells from bone marrow stroma defines the sequence of cellular and molecular events during chondrogenesis. Proc Natl Acad Sci USA 2002;99:4397-402

26 Schilham MW, Oosterwegel MA, Moerer P, Ya J, de Boer PA, van de Wetering M, Verbeek S, Lamers WH, Kruisbeek AM, Cumano A, Clevers H. Defects in cardiac outflow tract formation and pro-B-lymphocyte expansion in mice lacking Sox-4. Nature 1996;380:711-14.

27 Huang N, Lee I, Marcotte EM, Hurles ME. Characterising and predicting haploinsufficiency in the human genome. PLoS Genet 2010;6:e1001154

28 Visel A, Thaller C, Eichele G. GenePaint.org: an atlas of gene expression patterns in the mouse embryo. Nucleic Acids Res 2004;32(Database issue): D552-6.

29 Lettice LA, Daniels S, Sweeney E, Venkataraman S, Devenney PS, Gautier P, Morrison H, Fantes J, Hill RE, FitzPatrick DR. Enhancer-adoption as a mechanism of human developmental disease. Hum Mutat 2011;32:1492-9.

30 Spielmann M, Mundlos S. Structural variations, the regulatory landscape of the genome and their alteration in human disease. BioEssays 2013;35:533-43.

31 Spielmann M, Brancati F, Krawitz PM, Robinson PN, Ibrahim DM, Franke M, Hecht J, Lohan S, Dathe K, Nardone AM, Ferrari P, Landi A, Wittler L, Timmermann B, Chan D, Mennen U, Klopocki E, Mundlos S. Homeotic arm-to-leg transformation associated with genomic rearrangements at the PITX1 locus. Am J Hum Genet 2012;91:629-35

32 Giorgio E, Robyr D, Spielmann M, Ferrero E, Di Gregorio E, Imperiale D, Vaula G, Stamoulis G, Santoni F, Atzori C, Gasparini L, Ferrera D, Canale C, Guipponi M, Pennacchio LA, Antonarakis SE, Brussino A, Brusco A. A large genomic deletion leads to enhancer adoption by the lamin B1 gene: a second path to autosomal dominant leukodystrophy (ADLD). Hum Mol Genet 2015;24:3143-54.

33 Ibn-Salem J, Kohler S, Love MI, Chung HR, Huang N, Hurles ME, Haendel M, Washington NL, Smedley D, Mungall CJ, Lewis SE, Ott CE, Bauer S, Schofield PN, Mundlos S, Spielmann M, Robinson PN. Deletions of chromosomal regulatory boundaries are associated with congenital disease. Genome Biol 2014;15:423.

34 Lupiáñez DG, Kraft K, Heinrich V, Krawitz P, Brancati F, Klopocki E, Horn D, Kayserili H, Opitz JM, Laxova R, Santos-Simarro F, Gilbert-Dussardier B, Wittler $L$, Borschiwer M, Haas SA, Osterwalder M, Franke M, Timmermann B, Hecht J, Spielmann M, Visel A, Mundlos S. Disruptions of topological chromatin domains cause pathogenic rewiring of gene-enhancer interactions. Cell Published Online First: 6 May 2015. In press.

35 Tokuzawa Y, Yagi K, Yamashita Y, Nakachi Y, Nikaido I, Bono H, Ninomiya Y, Kanesaki-Yatsuka Y, Akita M, Motegi H, Wakana S, Noda T, Sablitzky F, Arai S, Kurokawa R, Fukuda T, Katagiri T, Schonbach C, Suda T, Mizuno Y, Okazaki Y. Id4, a new candidate gene for senile osteoporosis, acts as a molecular switch promoting osteoblast differentiation. PLoS Genet 2010;6:e1001019. 


\section{Microdeletions on 6p22.3 are associated with mesomelic dysplasia Savarirayan type}

Ricarda Flöttmann, Johannes Wagner, Karolina Kobus, Cynthia J Curry, Ravi Savarirayan, Gen Nishimura, Natsuo Yasui, Jürgen Spranger, Hilde Van Esch, Michael J Lyons, Barbara R DuPont, Alka Dwivedi, Eva Klopocki, Denise Horn, Stefan Mundlos and Malte Spielmann

J Med Genet 2015 52: 476-483 originally published online June 1, 2015 doi: 10.1136/jmedgenet-2015-103108

Updated information and services can be found at:

http://jmg.bmj.com/content/52/7/476

These include:

Supplementary Material

References

Email alerting service
Supplementary material can be found at:

http://jmg.bmj.com/content/suppl/2015/06/01/jmedgenet-2015-103108 .DC1.html

This article cites 33 articles, 10 of which you can access for free at: http://jmg.bmj.com/content/52/7/476\#BIBL

Receive free email alerts when new articles cite this article. Sign up in the box at the top right corner of the online article.

\section{Notes}

To request permissions go to:

http://group.bmj.com/group/rights-licensing/permissions

To order reprints go to:

http://journals.bmj.com/cgi/reprintform

To subscribe to BMJ go to:

http://group.bmj.com/subscribe/ 